\title{
Herdabilidade e Tendência Genética para as Produções de Leite e de Gordura em Rebanhos da Raça Holandesa no Estado do Rio Grande do Sul
}

\author{
Arione Augusti Boligon¹, Paulo Roberto Nogara Rorato², Gilka Berenice Barbosa Ferreira², \\ Tomás Weber ${ }^{3}$, Carlos Junior Kippert ${ }^{4}$, Juliano Andreazza ${ }^{5}$
}

\begin{abstract}
RESUMO - Com o objetivo de estimar a herdabilidade e a tendência genética para as características produção de leite (PL), produção de gordura (PG) e porcentagem de gordura (\%G), foram estudados registros de produção à primeira lactação de 5.007 vacas da raça Holandesa, filhas de 930 touros, pertencentes a 33 rebanhos criados no estado do Rio Grande do Sul entre 1984 e 1998. Para estimar as herdabilidades e predizer os valores genéticos dos indivíduos (VGs) para PL, PG e \%G, foi utilizado um modelo animal considerando-se como aleatórios os efeitos genético aditivo direto e residual e, como fixos, o número de ordenhas diárias, o rebanho e o ano/época do parto, além da covariável idade da vaca ao parto e dos efeitos linear e quadrático. Para o cálculo da tendência genética, utilizou-se a regressão dos VGs médios anuais em relação ao ano de nascimento dos animais. As médias observadas e os respectivos desvios-padrão foram de 6.862,80 $\pm 1.881,21 \mathrm{~kg} / \mathrm{ano}$ (PL), 228,63 \pm 78,01 kg/ano (PG) e 3,32 \pm 0,18 \%/ano (\%G). As herdabilidades estimadas e os respectivos erros-padrão foram de 0,30 \pm 0,008 (PL); 0,28 \pm 0,004 (PG) e 0,22 \pm 0,015 (\%G). As correlações genéticas estimadas foram 0,85 $\pm 0,19$ (PL e PG) e -0,15 $\pm 0,17$ (PL e $\% G$ ). As tendências genéticas estimadas foram de 9,51 kg/ano (PL), 0,11 kg/ano (PG) e -0,07\%/ano (\%G). Apesar de positivos, os ganhos genéticos estimados para PL e PG foram baixos, podendo ser aumentados pela implementação de programas de melhoramento genético eficientes que estimulem o produtor a promover aumentos nestas duas características, além das características de qualidade do leite.
\end{abstract}

Palavras-chave: bovinos de leite, parâmetros genéticos, progresso genético anual, seleção

\section{Heritability and Genetic Trend for Milk and Fat Yields in Holstein Herds Raised in the State of Rio Grande do Sul}

\begin{abstract}
Data comprising 5,007 records of first lactation of Holstein cows, daughters of 930 sires, from 33 herds in the state of Rio Grande do Sul, from 1984 to 1998, were used to estimate heritability coefficients and genetic trends for milk (MY) and fat (FY) yields and for fat percentage (\%F). An animal model considered the genetic additive direct and residual as random effects and milking/ day number, herd and year/season of parturition, and cow age at parturition as fixed effects, linear and quadratic effects, as covariate, inn order to estimate the coefficients of heritability and to predict the breeding values (BVs) for MY, FY and \%F. The genetic trend was estimated by the regression of mean annual animal BVs in relation to animal year birth. The averages and respective standard deviations for MY, FY and \%F were: 6,862.80 \pm 1,881.21 kg/year, $228.63 \pm 78.01 \mathrm{~kg} /$ year and $3.32 \pm .18 \%$ /year, respectively. The estimated coefficients of heritability and respective standard error for MY, FY and \%F were: $0.30 \pm 0.008 ; 0.28 \pm 0.004$ and $0.22 \pm 0.015$, respectively. The estimated genetic correlations were: $0.85 \pm 0.19$ and $-0.15 \pm 0.17$ for MY and FY and MY and F\%, respectively. The genetic trend for MY was of $9.25 \mathrm{~kg} /$ year, $0.11 \mathrm{~kg} /$ year for FP and $-0.07 \% /$ year for \%F. The values estimated for the coefficients of heritability suggest that it is possible to increase the rates for genetic gain for MP and FP, without change on \%F rate. The genetic gains for MY and FY were positive, but low, however they can be improved if breeding programs that stimulate the dairy man to increase both traits milk quality are implemented.
\end{abstract}

Key Words: annual genetic progress, dairy cattle, genetic parameters, selection

\section{Introdução}

Apesar de a exploração da raça Holandesa ser antiga no Brasil, ainda há muito por fazer no melhoramento genético e nas condições de criação adotadas, principalmente pelo fato de que esta população, como raça pura ou como base para cruzamentos, é respon- sável por considerável parcela da produção de leite em nosso país.

A tentativa mais utilizada para aumentar a eficiência de nossa pecuária leiteira tem sido a transferência de modernas tecnologias e produtos oriundos de países desenvolvidos, sem, contudo, considerar as bases sobre as quais estes sistemas foram desenvolvidos. A

\footnotetext{
${ }^{1}$ Aluno do curso de Zootecnia, bolsista CNPq/PIBIC-Campus Universitário, CEP: 97105-900, Santa Maria, RS. E.mail: arioneb@bol.com.br 2 Prof. Departamento de Zootecnia da Universidade Federal de Santa Maria.

3 Aluno de curso de Zootecnia, bolsista FAPERGS.

${ }^{4}$ Aluno de Pós-graduação em Zootecnia da Universidade Federal de Santa Maria.

5 Médico Veterinário, Msc. em Zootecnia.
} 
prática de transferência de sêmen, embriões e matrizes da raça Holandesa de países com pecuária adiantada para o Brasil o coloca na condição exclusiva de país importador e, portanto, dependente.

O controle e o acompanhamento da genética dos rebanhos é, atualmente, uma técnica indispensável, uma vez que, com base nas informações fornecidas por este acompanhamento é que são tomadas decisões relacionadas à seleção, necessárias para a continuidade do melhoramento genético destes rebanhos.

A herdabilidade mede a influência da variação genética em relação à variação total de uma característica em uma população. É uma propriedade não somente de caractere, mas também da população. As correlações genéticas entre as características produtivas nos indicam se há antagonismo entre os genes responsáveis pelas mesmas, auxiliando na escolha dos reprodutores de acordo com objetivos a serem alcançados. Por isso, para definir planos de melhoramento genético, a estimativa da herdabilidade e das correlações genéticas para características de produção é um parâmetro fundamental. Com base em seu valor e na intensidade da seleção praticada, pode-se estimar a taxa de progresso genético ao longo das gerações.

A estimativa de tendência genética, quando avaliada periodicamente, nos permite verificar a eficiência dos programas de melhoramento genético animal. Seu conhecimento pode auxiliar em decisões em relação ao futuro e na verificação da eficácia da escolha dos reprodutores por parte do criador. Uma das formas de se realizar este acompanhamento é por meio da determinação do progresso genético observado em características sob seleção na população.

Este trabalho foi conduzido com o objetivo de se estimarem os coeficientes de herdabilidade e as tendências genéticas para as produções de leite e de gordura e para o percentual de gordura do leite, em rebanhos da raça Holandesa no estado do Rio Grande do Sul.

\section{Material e Métodos}

Este trabalho foi realizado com dados coletados pelo serviço de controle leiteiro da Associação de Criadores de Bovinos da Raça Holandesa do estado do Rio Grande do Sul. Os arquivos continham registros de produção à primeira lactação de 5.007 vacas da raça Holandesa, filhas de 930 touros da mesma raça, por meio de inseminação artificial, nascidas entre os anos de 1984 e 1998 e provenientes de 33 rebanhos distribuídos em diferentes regiões do estado.

As progênies produzidas pelos reprodutores em gerações sucessivas aumentam a amostra da herança genética que eles estão transmitindo à descendência e permitem a obtenção de estimativas de herdabilidade e de tendências genéticas mais acuradas.

Os componentes de variância e covariância utilizados para se estimar os coeficientes de herdabilidade e predizer o valor genético (VG) dos indivíduos para as características de produção de leite (PL), produção de gordura (PG) e porcentagem de gordura $(\% \mathrm{G})$, foram estimados utilizando-se o aplicativo MTDFREML (Multiple Trait Derivative Free Restricted Maximun Likelihood), descrito por Boldman et al. (1995). Utilizou-se um modelo animal que incluiu como aleatórios os efeitos, genético direto do animal e residual e, como fixos, os efeitos de número de ordenhas diárias, de rebanho e de ano/época do parto e, como covariável, a idade da vaca ao parto, linear e quadrática. Este modelo foi utilizado para as três características em análises unicaracterísticas e para estimação da correlação entre PL e PG e PL e \%G, em análise bicaracterística. A matriz de parentesco constituiu-se de 4.985 pedigrees lidos.

$$
\begin{aligned}
Y_{i j k l}=\mu+g_{i}+A E_{j} & +R_{k}+O_{l}+\hat{a}_{1}\left(I_{i j k l}-I\right)+\hat{a}_{2}\left(I_{i j k l}\right. \\
& -I)^{2}+\varepsilon_{i j k l}
\end{aligned}
$$

em que $Y_{i j k l}=$ registro das produções de leite, de gordura ou da porcentagem de gordura, do animal i; $\mu=$ constante representando a média geral; $\mathrm{g}_{\mathrm{i}}=$ efeito genético direto do iésimo animal, aleatório; $\mathrm{AE}_{\mathrm{j}}=$ efeito fixo do jiésimo ano-época em que ocorreu o parto; $\mathrm{R}_{\mathrm{k}}=$ efeito fixo do $\mathrm{k}^{\text {iésimo }}$ rebanho; $\mathrm{O}_{\mathrm{l}}=$ efeito fixo do número de ordenhas diárias; $\beta_{1}$ e $\beta_{2}=$ efeitos das regressões linear e quadrática, de $\mathrm{Y}_{\mathrm{ijkl}}$, em função da idade da vaca ao parto; $\mathrm{I}_{\mathrm{ijkl}}$ = idade ao parto, em meses, na lactação l, ocorrida no ano-estação de parto j, da vaca i, do rebanho k; I = idade média das vacas ao parto, em meses; $\varepsilon_{\mathrm{ijkl}}=$ efeito residual, associado a cada observação, aleatório.

Com o objetivo de aumentar a consistência dos dados, foram utilizadas as informações de animais com idades ao parto menores que 36 meses e períodos de lactação superiores a 100 dias. Foi criada uma variável denominada ano/época do parto, sendo con- 
sideradas duas épocas, uma de abril a setembro (outono-inverno) e outra de outubro a março (primavera-verão).

A tendência genética para as características de PL, PG e \%G foi estimada a partir das médias anuais dos VGs dos animais. A partir desses valores, calculou-se a regressão dos VGs médios anuais estimados em relação ao ano de nascimento do animal, segundo o modelo de regressão:

$$
\hat{Y}_{\mathrm{k}}=\mathrm{b}_{0}+\mathrm{b}_{1} \mathrm{X}_{\mathrm{k}}
$$

em que $\hat{Y}_{\mathrm{k}}=$ VG médio do $\mathrm{k}^{\text {ésimo }}$ ano de nascimento; $\mathrm{X}_{\mathrm{k}}=\mathrm{k}^{\text {ésimo }}$ ano de nascimento; $\mathrm{b}_{0}=$ constante da equação; $b_{1}=$ coeficiente de regressão linear.

Com isso, tornou-se possível estimar, por meio da regressão linear, o ganho genético anual verificado nesta população, para as características de PL, PG e \%G.

A seguir estão apresentadas, na Tabela 1, a distribuição dos dados e as médias observadas para as três características avaliadas na população estudada.

\section{Resultados e Discussão}

As médias observadas e os respectivos desviospadrão para as produções de leite (PL) e de gordura (PG) no período estudado foram iguais a 6.862,80 \pm
$1.881,21 \mathrm{~kg} /$ ano e $228,63 \pm 78,01 \mathrm{~kg} / \mathrm{ano}$, respectivamente. Esses valores se assemelham aos relatados por Tonhati \& Lôbo (1997), Pimpão et al. (1997), Araújo et al. (2000), Durães et al. (2000) e Rorato et al. (2002), que encontraram valores entre 5.190,20 e $6.876,00 \mathrm{~kg}$, para PL, e entre 175,00 e 228,50 kg, para PG, em rebanhos da raça Holandesa no Brasil.

A porcentagem média de gordura observada $(\% \mathrm{G})$ e o respectivo desvio-padrão no período foram iguais a 3,32 $\pm 0,18 \% /$ ano, semelhantes aos resultados relatados por Pimpão et al. (1997), Bajaluk et al. (1999) e Rorato et al. (2002), que obtiveram valores entre 3,27 e 3,40, para animais da raça Holandesa no Brasil.

As médias encontradas para PL e PG indicam que as populações estudadas possuem índices produtivos superiores aos relatados por Marion (2000), que, revisando estudos de rebanhos da raça Holandesa no país, encontrou média de 4.944 kg/ano, para PL, e de 186,7 kg/ano, para PG.

As estimativas de herdabilidade e os respectivos erros-padrão obtidos nesse estudo foram $0,30 \pm 0,008$, para PL, e de 0,28 $\pm 0,004$, para PG. Estas estimativas são superiores aos valores relatados para a raça Holandesa por Ferreira \& Fernandes (2000), Marion (2000) e Freitas et al. (2001), que variaram de 0,18 a 0,28, para PL, e de 0,18 a 0,21, para PG. Trabalhando com a mesma raça, Torres et al. (1999) e Weber et al. (2005) relataram valores inferiores ao deste estudo

Tabela 1 - Número de observações, médias observadas e respectivos desvios-padrão para características de produção de leite $(P L)$, produção de gordura (PG) e porcentagem de gordura (\%G), por ano de nascimento da vaca

Table 1 - Number of observations, observed means and respective standard deviations for milk (MP) and fat (FP) yields and fat percentage $(\% \mathrm{~F})$, according to cow birth year

\begin{tabular}{lcccc}
\hline $\begin{array}{l}\text { Ano } \\
\text { Year }\end{array}$ & $\begin{array}{c}\text { Número } \\
\text { Number }\end{array}$ & $\begin{array}{c}\text { PL }(\mathrm{kg}) \\
M P(\mathrm{~kg})\end{array}$ & $\begin{array}{c}\text { PG }(\mathrm{kg}) \\
F P(\mathrm{~kg})\end{array}$ & $\begin{array}{c}\% G \\
\% F\end{array}$ \\
\hline 1984 & 301 & $4.485,9 \pm 1.115$ & $179,1 \pm 73$ & $3,40 \pm 0,12$ \\
1985 & 341 & $4.521,6 \pm 1.412$ & $195,4 \pm 54$ & $3,37 \pm 0,11$ \\
1986 & 328 & $5.712,9 \pm 1.124$ & $168,6 \pm 43$ & $3,41 \pm 0,10$ \\
1987 & 451 & $4.681,4 \pm 1.007$ & $214,2 \pm 55$ & $3,24 \pm 0,16$ \\
1988 & 368 & $5.996,8 \pm 1.359$ & $229,3 \pm 51$ & $3,05 \pm 0,10$ \\
1989 & 298 & $6.946,4 \pm 1.458$ & $239,8 \pm 62$ & $3,45 \pm 0,14$ \\
1990 & 320 & $5.832,2 \pm 1.532$ & $241,4 \pm 51$ & $3,35 \pm 0,15$ \\
1991 & 341 & $5.725,6 \pm 1.154$ & $230,1 \pm 62$ & $3,32 \pm 0,19$ \\
1992 & 296 & $6.541,5 \pm 1.147$ & $222,3 \pm 61$ & $3,25 \pm 0,17$ \\
1993 & 348 & $6.621,9 \pm 1.451$ & $245,6 \pm 59$ & $3,24 \pm 0,14$ \\
1994 & 365 & $7.587,1 \pm 1.871$ & $254,2 \pm 61$ & $3,29 \pm 0,11$ \\
1995 & 321 & $6.897,2 \pm 1.099$ & $210,1 \pm 40$ & $3,34 \pm 0,14$ \\
1996 & 301 & $6.945,8 \pm 1.154$ & $275,2 \pm 47$ & $3,26 \pm 0,11$ \\
1997 & 328 & $7.487,5 \pm 1.241$ & $259,1 \pm 51$ & $3,41 \pm 0,16$ \\
1998 & 300 & $7.958,2 \pm 1.108$ & $265,1 \pm 49$ & $3,32 \pm 0,18$ \\
Média & 333,8 & $6.862,8 \pm 1.881$ & $228,6 \pm 78$ & \\
Mean & & & & \\
\hline
\end{tabular}


para PL $(0,22)$ e superiores para PG $(0,36$ e 0,49 respectivamente). Por outro lado, Matos et al. (1997) estimaram coeficientes de herdabilidade para PL e PG superiores aos deste estudo (0,35 e 0,34, respectivamente), para a raça Holandesa no Rio Grande do Sul.

Para a característica \%G, o valor da estimativa para o coeficiente de herdabilidade e o respectivo erro-padrão, neste trabalho, foi 0,22 $\pm 0,015$, inferior ao relatado por Barbosa et al. (1994), de 0,52 $\pm 0,11$ para raça Holandesa, no estado de Pernambuco.

Os valores dos coeficientes de herdabilidade estimados indicam que a variância genética aditiva é responsável por considerável parcela da variância fenotípica, sugerindo que podem ser obtidos, por meio de seleção, ganhos genéticos significativos para as características PL, PG e \%G. Neste cenário, é de fundamental importância promover junto ao criador a utilização de touros selecionados, com VGs superiores, buscando realizar o ganho genético.

A correlação genética estimada entre PL e PG foi de $0,82 \pm 0,19$. Este valor é inferior aos relatados por Barbosa et al. (1994), Matos et al. (1997) e Ferreira \& Fernandes (2000), de 0,90; 0,95 e 0,98, respectivamente, para raça Holandesa. Freitas et al. (2001) relataram correlações genéticas altas entre estas duas características $(0,86$ a 1,00$)$ para animais da raça Holandesa em diferentes lactações, o que sugere que estas características estão, em parte, sob o efeito dos mesmos tipos de genes. Portanto, a seleção para aumentar a quantidade de leite produzida também melhoraria a produção de gordura do leite.

A correlação genética entre PL e \%G foi $-0,15 \pm$ 0,17 , indicando que essas características são determinadas, em parte, por diferentes grupos de genes, que respondem de forma diferenciada às condições ambientais. A seleção para elevar a produção de leite não é acompanhada de aumento proporcional na de gordura, tendo, como consequiência, decréscimo no percentual da PG, o que explica a correlação genética negativa. Este valor é similar ao de -0,11, para raça Gir, relatado por Balieiro et al. (2000), ao afirmarem que os fatores de ambiente foram os responsáveis pela significativa mudança fenotípica na porcentagem de gordura.

Na Figura 1 encontra-se a estimativa de tendência genética para PL, que foi de 9,51 kg/ano $(\mathrm{p}<0,05)$. Esse valor é superior ao relatado por Freitas et al. (1995) que estimaram mudança genética de $-11,77 \mathrm{~kg} /$ ano, para animais da raça Holandesa criados na região Sudeste do país, no período de 1977 a 1992.
Autores como Houri Neto et al. (1996), avaliando vacas nascidas entre os anos de 1974 a 1990 nos Estados Unidos e no Brasil, e Rorato et al. (2002), analisando rebanhos leiteiros criados no estado do Rio Grande do Sul, no período de 1988 a 1998, estimaram tendência genética para PL igual a 8,43 kg/ano, para a raça Holandesa. Tendências genéticas superiores às encontradas neste trabalho foram relatadas por Durães et al. (2001), para animais nascidos entre os anos de 1986 e 1996 (18,4 kg/ano), e por Teixeira et al. (2003), para vacas nascidas entre os anos 1986 e 1999 (19,1 kg/ ano), ambos trabalhando com rebanhos da raça Holandesa criados no estado de Minas Gerais.

Esta variação nos valores de tendência genética pode ser causada por diferentes fatores, entre os quais destaca-se a utilização de sêmen de touros nãoprovados, de menor preço, visando reduzir os custos. Segundo Araújo et al. (2003), outra possível explicação para baixos valores de estimativas de tendência genética é o fluxo desorganizado do melhoramento genético, o qual só é praticado em uma pequena fração de rebanhos e individualmente; isto é, cada produtor adota seus próprios critérios de seleção, independentemente dos demais. Isso pode fazer com que rebanhos de mérito genético inferior forneçam reprodutores para rebanhos de maior mérito genético, provocando um retrocesso na seleção. Neste cenário, a seleção de animais para PL e PG com base na utilização de reprodutores com VGs superiores aos da população onde serão introduzidos, tenderá a

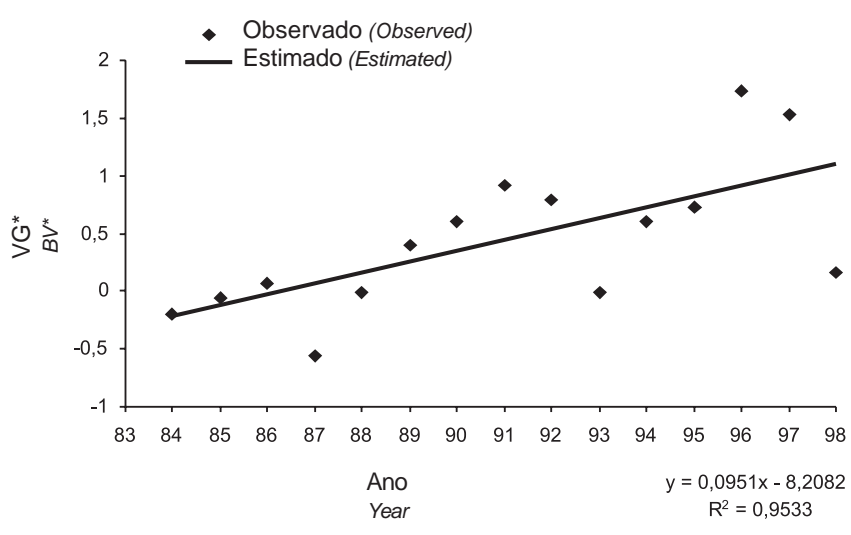

*VG $=$ Valor genético $(B V=$ Breeding value $)$

Figura 1 - Tendência genética para produção de leite. Figure 1 - Genetic trend for milk yield. 
maximizar a tendência genética anual e, conseqüentemente, a produtividade dos rebanhos.

Na Figura 2 encontra-se a estimativa de tendência genética para PG, que foi de $0,11 \mathrm{~kg} / \mathrm{ano}(\mathrm{p}<0,05)$, inferior à relatada por Durães et al. (2001), que, trabalhando com vacas da raça Holandesa no estado de Minas Gerais, nascidas entre os anos de 1986 a 1996, encontraram tendência de 0,6 kg/ano. São, também, observados na literatura valores próximos a zero e até mesmo negativos, como os relatados por Silva et al. (2001), para mestiços do Ecótipo Mantiqueira, no estado de São Paulo, no período de 1952 a 1997, por Freitas et al. (1995) para rebanhos da raça Holandesa, pertencentes a diferentes regiões brasileiras, e por Tonhati \& Lôbo (1997), para animais da raça Holandesa nascidos no estado de São Paulo em 12 anos consecutivos. Esses autores estimaram tendências anuais iguais a 0,06; -0,22 e -1,9 kg, respectivamente.

As tendências genéticas estimadas neste estudo para a PL e PG apresentam comportamento semelhante, demonstrando ganhos genéticos maiores no decorrer dos anos, confirmando os relatos de Araújo et al. (2003), com exceção dos anos de 1993 e 1998, em que os ganhos foram próximos a zero para produção de leite e negativos para produção de gordura.

Os valores estimados para a tendência genética anual indicam que houve ganho para característica PL, provavelmente como reflexo daqueles rebanhos em que são utilizados touros com maior valor genético

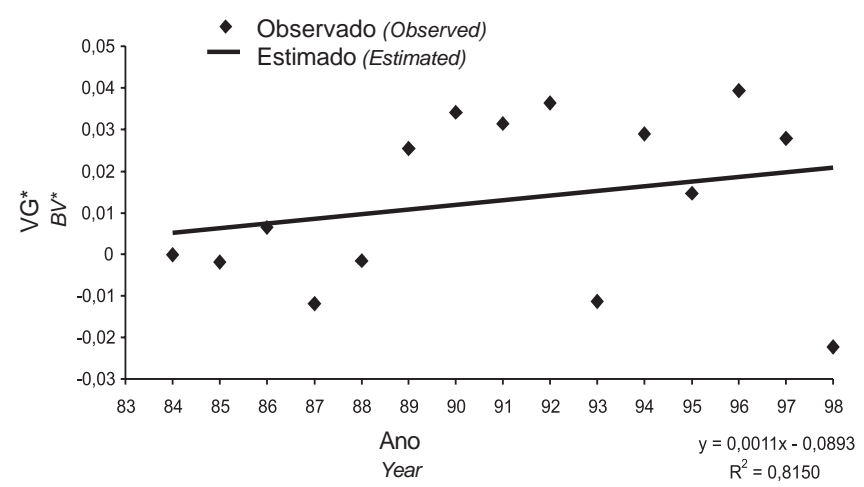

*VG $=$ Valor genético $(B V=$ Breeding value $)$

Figura 2 - Tendência genética para produção de gordura. Figure 2 - Genetic trend for fat yield. para esta característica, nesta população. Pela correlação genética positiva e alta entre a PL e PG, provavelmente o ganho genético obtido em PG ocorreu em função do ganho obtido em PL, pelo fato de os genes responsáveis pela expressão destas características serem, em grande parte, comuns; ou seja, ao serem selecionados animais para elevar a produção de leite, estes apresentaram também maior produção de gordura.

Os ganhos genéticos anuais para PL e PG, embora positivos, foram de baixa magnitude, correspondendo a 0,14 e 0,05\% das médias de produção de leite e de gordura, respectivamente. A maioria dos estudos de tendência genética no país indicam que a seleção e o uso de indivíduos considerados superiores têm conduzido, ainda que de forma lenta, a mudanças positivas nas médias das características de produção de leite e de gordura para a raça Holandesa. Entretanto, estas produções podem ser aumentadas com a disseminação organizada de animais com valores genéticos superiores, responsáveis pelo incremento nas produções de leite e gordura.

Na Figura 3 encontra-se a estimativa de tendência genética para \%G, igual a $-0,07 \% / a n o(p<0,05)$. Este valor é inferior ao relatado por Freitas et al. (1995) e Balieiro et al. (2000) para raça Holandesa, os quais estimaram ganhos de 0,0032 e 0,0390\%/ano, respectivamente. Entretanto, são superiores aos resultados obtidos por Rorato et al. (2002), que relataram valores de $-0,0015 \% / a n o$.

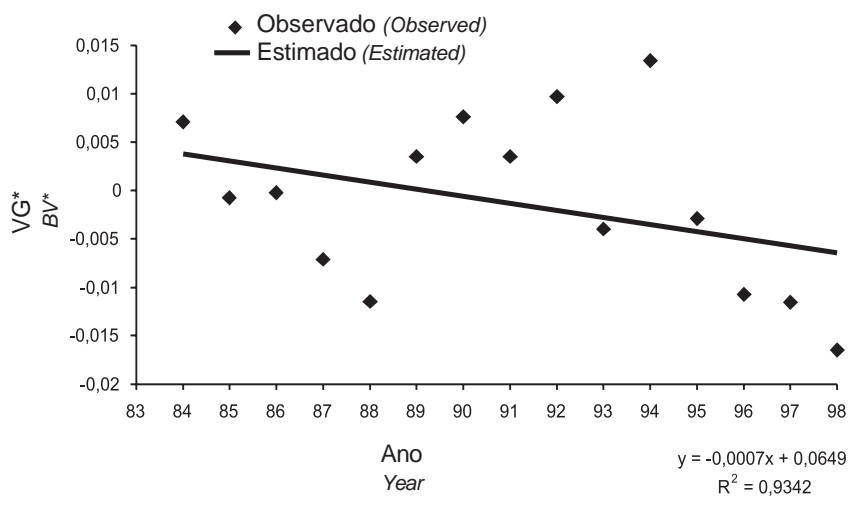

*VG $=$ Valor genético $(B V=$ Breeding value $)$

Figura 3 - Tendência genética para porcentagem de gordura.

Figure 3 - Genetic trend for fat percentage. 
Esta tendência negativa para a \%G deve ter ocorrido em razão da maior preocupação, por parte dos produtores, em selecionar seus rebanhos para PL. Como PL apresenta correlação genética negativa com \%G, houve pequena redução no valor genético para esta característica. Resultado semelhante foi verificado por Balieiro et al. (2000), que relataram estimativas de ganho genético para característica de \%G baixas e próximas a zero, para rebanhos da raça Gir.

A comparação das tendências genéticas estimadas neste trabalho para PL e PG com as observadas na literatura, para a raça Holandesa, demonstra a possibilidade de se obter maior progresso genético nesta população e, conseqüentemente, na produtividade. Para que isto ocorra, é necessário que sejam adotados, pelos produtores, critérios básicos de seleção que aumentem a acurácia na identificação dos reprodutores com VGs mais elevados que promovam a utilização dos mesmos com maior freqüência nos acasalamentos.

O aumento observado nas médias para a produção de leite ao longo dos anos estudados pode ser decorrente de melhorias no meio ambiente, como manejo, condições sanitárias e nutrição, oferecidas aos animais, e não da seleção ou da introdução de genes superiores nessa população, visto que o ganho genético obtido ao longo destes 14 anos está aquém do pretendido.

\section{Conclusões}

Os coeficientes de herdabilidade estimados para as características analisadas foram moderados, indicando que uma parcela relativamente grande da variação observada nas características analisadas é decorrente de diferenças nos genes de efeito aditivo, sugerindo ser possível alcançar progresso genético nesta população por meio de seleção.

Embora positivos, os ganhos genéticos para produções de leite e de gordura foram baixos, indicando que, caso tenha havido, os processos seletivos nestes rebanhos não foram eficientes, refletindo a necessidade de implementação de programas de melhoramento que utilizem touros com valores genéticos altos e positivos para estas duas características.

A tendência genética negativa estimada para a porcentagem de gordura indica que o ganho obtido para as características de produção não foi transferido para a qualidade do leite, sugerindo a necessidade de programas de incentivo, como os de pagamento pela qualidade, para que o produtor considere estes quesitos ao tomar decisões sobre a aquisição de sêmen e/ou de reprodutores.

\section{Agradecimento}

À Associação de Criadores de Bovinos da Raça Holandesa no Estado do Rio Grande do Sul pelo favorecimento das informações utilizadas neste estudo. Ao Conselho Nacional de Desenvolvimento Científico e Tecnológico (CNPq) e à Fundação de Amparo à Pesquisa do Estado do Rio Grande do Sul (FAPERGS), pelo apoio financeiro.

\section{Literatura Citada}

ARAÚJO, C.V.; TORRES, R.A.; RENNÓ, F.P. et al. Tendência genética para características produtivas em bovinos da raça Pardo-Suíça. Revista Brasileira de Zootecnia, v.32, n.6, p.1872-1877, 2003. (suplemento 2).

ARAÚJO, C.V.; GONÇALVES, T.M.; AQUINO, L.H. et al. Fatores não genéticos nas produções de leite e de gordura em rebanhos da raça Holandês no estado de Minas Gerais. Ciência Agrotécnica, v.24, n.3, p.766-772, 2000.

BALIEIRO, E.S.; PEREIRA, J.C.C.; VALENTE, J. et al. Estimativas de parâmetros genéticos e de tendências fenotípica, genética e de ambiente de algumas características produtivas da raça Gir leiteiro. Arquivo Brasileiro de Medicina Veterinária e Zootecnia, v.52, n.3, p.266-275, 2000.

BAJALUK, S.A.B.; RIBAS, N.P.; MONARDES, H.G. et al. Efeito de fatores ambientais sobre a produção de leite, percentagem de gordura e percentagem de proteína em vacas da raça Holandesa no estado do Paraná. In: REUNIÃO ANUAL DA SOCIEDADE BRASILEIRA DE ZOOTECNIA, 36., 1999, Porto Alegre. Anais... Porto Alegre: Sociedade Brasileira de Zootecnia, 1999. p.158.

BARBOSA, S.B.P.; MILAGRES, J.C.; CASTRO, A.C.G. et al. Estudo da produção e percentagem de gordura do leite em rebanhos Holandeses, no estado de Pernambuco. Revista Brasileira de Zootecnia, v.23, n.3, p.485-495, 1994.

BOLDMAN, K.G.; KRIESE, L.A.; Van VLECK, L.D. et al. A manual for use of MTDFREML - A set of program to obtain estimates of variances and covariances (DRAFT). Lincoln: Departament of Agriculture/Agricultural Research Service, 1995. 120p.

DURÃES, M.C.; FREITAS, A.F.; TEIXEIRA, M.N. et al. Fatores de ajustamento da produção de leite e de gordura na raça Holandesa para idade e núcleo de controle leiteiro. Arquivo Brasileiro de Medicina Veterinária e Zootecnia, v.52, n.2, p.171-184, 2000.

DURÃES, M.C.; FREITAS, A.F.; VALENTE, J. et al. Tendência genética para produção de leite e de gordura em rebanhos da raça Holandesa no estado de Minas Gerais. Revista Brasileira de Zootecnia, v.30, n.1, p.66-70, 2001.

FERREIRA, G.B.; FERNANDES, H.D. Parâmetros genéticos para as características produtivas em bovinos da raça Holandesa no estado de Goiás. Revista Brasileira de Zootecnia, v.29, n.2, p.421-426, 2000. 
FREITAS, A.F.; DURÃES, M.C.; VALENTE, J. et al. Parâmetros genéticos para produção de leite e gordura nas três primeiras lactações de vacas Holandesas. Revista Brasileira de Zootecnia, v.30, n.3, p.709-713, 2001.

FREITAS, A.F.; WILCOX, C.J.; COSTA, C.J. Genetics trends in the production of Brazilian dairy crossbreds. Revista Brasileira de Genética, v.18, n.1, p.55-62, 1995.

HOURI NETO, M.; SILVA, H.M.; BERGMANN, J.A.C. Tendência genética para produção de leite na raça Holandesa no Brasil e nos Estados Unidos da América. Arquivo Brasileiro de Medicina Veterinária e Zootecnia, v.48, n.6, p.755-762, 1996.

MARION, A.E. Estudo da variação nas estimativas de componentes de variância e coeficientes de herdabilidade para as características de produção da raça Holandesa no Rio Grande do Sul. Santa Maria: Universidade Federal de Santa Maria: Universidade Federal de Santa Maria, 2000. 89p. Dissertação (Mestrado) - Universidade Federal de Santa Maria, 2000.

MATOS, R.S.; RORATO, P.R.N.; FERREIRA, G.B. et al. Estudos dos efeitos genéticos e de meio ambiente sobre a produção de leite e gordura da raça Holandês no Estado do Rio Grande do Sul. Revista Ciência Rural, v.27, n.3, p.465-471, 1997.

PIMPÃO, C.T.; RIBAS, N.P.; MONARDES, H. G. et al. Estudo dos efeitos de meio ambiente sobre as caracteristicas produtivas de vacas da raça holandesa da região de Arapoti, estado do Paraná. Revista Brasileira de Zootecnia, v.27, n.3, p.494-500, 1997.

RIBAS, N.P.; MONARDES, H.; MOLENTO, C.F.M. et al. Estudo dos efeitos de meio ambiente sobre características produtivas de vacas da raça holandesa no estado do Paraná. In: REUNIÃO ANUAL DA SOCIEDADE BRASILEIRA DE ZOOTECNIA, 33., 1996, Fortaleza. Anais... Fortaleza: Sociedade Brasileira de Zootecnia, 1996. p.9-11.

RORATO, P.R.N.; EVERLING, D.M.; VARGAS, A.D.F. et al. Estudo da tendência genética para as características de produção e de qualidade do leite em rebanhos da raça Holandesa no estado do Rio Grande do Sul. In: REUNIÃO ANUAL DA SOCIEDADE BRASILEIRA DE ZOOTECNIA, 39., 2002, Recife. Anais... São Paulo: Sociedade Brasileira de Zootecnia/ Gnosis, 2002. CD-ROM. Melhoramento Animal.
SILVA, M.V.G.B.; FERREIRA, W.J.; COBUCI, J.A. et al. Estimativas de tendência genética para características produtivas em um rebanho do Ecótipo Mantiqueira. Revista Brasileira de Zootecnia, v.30, n.5, p.1466-1475, 2001.

TEIXEIRA, N.M.; FERREIRA, W.J.; TORRES, R.A. et al. Tendência genética para produção de leite na raça Holandesa no estado de Minas Gerais. In: REUNIÃO ANUAL DA SOCIEDADE BRASILEIRA DE ZOOTECNIA, 40., 2003, Santa Maria. Anais... Santa Maria: Sociedade Brasileira de Zootecnia/Gnosis, 2003. CD-ROM. Melhoramento Animal.

TONHATI, H.; LÔBO, R.B. Estimativas de mudança genética na produção de leite e gordura em bovinos da raça Holandesa. Revista Brasileira de Zootecnia, v.26, n.4, p.714-718, 1997.

TORRES, R.A.; BERGMAN, J. A.G.; COSTA, C.N. et al. Ajustamento para heterogeneidade de variância para produção de leite entre rebanhos da raça Holandesa no Brasil. Revista Brasileira de Zootecnia, v.28, n.2, p.295-303, 1999.

WEBER, T.; RORATO, P.R.N; FERREIRA, G.B.B. et. al. Coeficientes de herdabilidade e correlações genéticas para as produções de leite e de gordura, em diferentes níveis de produção, para raça holandesa no estadado do Rio Grande do Sul. Revista Brasileira de Zootecnia, v.34, n.2, p.514-519, 2005. 